\title{
Do $\Delta^{9}$-Tetrahydrocannabinol Concentrations Indicate Recent Use in Chronic Cannabis Users?
}

\author{
Erin L. Karschner, B.A. ${ }^{1}$, Eugene W. Schwilke, B.S. ${ }^{1}$, Ross H. Lowe, Ph.D. ${ }^{1}$, W. David \\ Darwin, B.S. ${ }^{1}$, Harrison G. Pope Jr, Ph.D. ${ }^{2}$, Ronald Herning, Ph.D. ${ }^{3}$, Jean Lud Cadet, M.D. ${ }^{3}$, \\ and Marilyn A. Huestis, Ph.D., ${ }^{1,}$ \\ ${ }^{1}$ Chemistry and Drug Metabolism, National Institute on Drug Abuse, National Institutes of Health, \\ 251 Bayview Blvd. Suite 200, Baltimore, MD 21224 USA \\ ${ }^{2}$ Department of Psychiatry, Harvard Medical School, and Biological Psychiatry Laboratory, \\ McLean Hospital 115 Mill Street, Belmont, MA 02478 USA
}

${ }^{3}$ Molecular Neuropsychiatry, Intramural Research Program, National Institute on Drug Abuse, National Institutes of Health, 251 Bayview Blvd. Suite 200, Baltimore, MD 21224 USA

\begin{abstract}
AIMS - To quantify blood $\Delta^{9}$-tetrahydrocannabinol (THC) concentrations in chronic cannabis users over seven days of continuous monitored abstinence.
\end{abstract}

PARTICIPANTS-Twenty-five frequent, long-term cannabis users resided on a secure clinical research unit at the U.S. National Institute on Drug Abuse under continuous medical surveillance to prevent cannabis self-administration.

MEASUREMENTS-Whole blood cannabinoid concentrations were determined by twodimensional gas chromatography-mass spectrometry.

FINDINGS-Nine chronic users (36\%) had no measurable THC during seven days of cannabis abstinence; 16 had at least one positive THC $\geq 0.25 \mathrm{ng} / \mathrm{mL}$, but not necessarily on the first day. On day 7 , six full days after entering the unit, six participants still displayed detectable THC concentrations (mean $\pm \mathrm{SD}, 0.3 \pm 0.7 \mathrm{ng} / \mathrm{mL}$ ) and all 25 had measurable carboxy-metabolite $(6.2 \pm$ $8.8 \mathrm{ng} / \mathrm{mL}$ ). The highest observed THC concentrations on admission (day 1) and day 7 were 7.0 and $3.0 \mathrm{ng} / \mathrm{mL}$, respectively. Interestingly, five participants, all female, had THC positive whole blood specimens all seven days. Body mass index did not correlate with time until last THC positive specimen $(N=16 ; \mathrm{R}=-0.2 ; p=0.445)$.

CONCLUSIONS-Substantial whole blood THC concentrations persist multiple days after drug discontinuation in heavy chronic cannabis users. It is currently unknown whether neurocognitive impairment occurs with low blood THC concentrations, and whether return to normal performance, as previously documented following extended cannabis abstinence, is accompanied by removal of residual THC in brain. These findings also may impact the implementation of per se limits in driving under the influence of drugs legislation.

"Corresponding Author Marilyn A. Huestis, PhD, Chief, Chemistry and Drug Metabolism, Intramural Research Program, NIDA, NIH, Biomedical Research Center Suite 200, 251 Bayview Blvd. Room 05A-721, Baltimore, MD 21224 USA,

mhuestis@intra.nida.nih.gov.

The authors have no conflicts of interest to report.

DECLARATIONS OF INTEREST

None. 


\section{INTRODUCTION}

Cannabis, the most widely used illicit drug worldwide, exerts dose-related psychoactive effects when the primary psychoactive component, $\Delta^{9}$-tetrahydrocannabinol (THC), interacts with cannabinoid receptors in brain. THC binding to the CB1-cannabinoid receptor leads to the "high" experienced by cannabis smokers [1]. THC is metabolized by hepatic cytochrome $\mathrm{P} 450$ enzymes 2C9 and 2C19 to the equipotent monohydroxy compound [2], 11-hydroxy-THC (11-OH-THC), and undergoes further oxidation to non-psychoactive 11nor-9-carboxy-THC (THCCOOH) [3,4]. Whole blood 11-OH-THC concentrations are only about $10 \%$ of THC concentrations after smoking cannabis, in comparison to nearly equivalent concentrations after oral THC administration [5]. First pass hepatic metabolism of orally administered cannabis greatly reduces the bioavailability of THC by this route, but does produce increased 11-OH-THC concentrations that contribute to observed pharmacodynamic effects. While THC concentrations decrease rapidly after smoking cannabis, THCCOOH concentrations, the water soluble metabolite, are detected for longer periods of time in blood [6]. For best interpretation of cannabinoid blood concentrations and an improved understanding of THC disposition in biological matrices, quantification of THC, 11-OH-THC and THCCOOH is needed. In addition, predictive models to estimate time of last cannabis use within $95 \%$ confidence intervals require concentration data for THC and THCCOOH [7-9], and THC and 11-OH-THC concentrations may suggest whether the route of administration was smoked or oral.

Dose-related cognitive and psychomotor performance, such as that related to driving a motor vehicle, may be impaired when under the influence of cannabis [10-15]. Another body of data suggests that residual neuropsychological deficits may persist in chronic cannabis users for days or even weeks after last drug exposure $[16,17]$. Although the mechanism of these residual cognitive and motor deficits is uncertain, it seems likely that they might be attributable to the persistence of cannabinoids in the blood, and by implication, in the brain.

One important reason for evaluating THC disposition after chronic cannabis exposure is that impairment is sometimes inferred in forensic settings on the basis of THC concentrations in whole blood. In 15 states (Arizona, Delaware, Georgia, Illinois, Indiana, Iowa, Michigan, Nevada, North Carolina, Ohio, Pennsylvania, Rhode Island, South Dakota, Utah and Wisconsin) and 7 European countries (Belgium, France, Finland, Germany, Poland, Sweden and Switzerland), per se legal limits are set for blood cannabinoid concentrations; if whole blood THC concentrations equal or exceed the legal limit, drivers may be convicted of driving under the influence of drugs (DUID). But do blood cannabinoid concentrations reflect recency of cannabis exposure in heavy long-term cannabis users? Despite the importance of this question, few studies have been conducted that include observed abstinence and extended monitoring periods $[18,19]$. To augment these limited data, we measured serial blood cannabinoid concentrations during seven days of monitored abstinence in 25 of the heaviest, longest-term cannabis users volunteering for our clinical studies.

\section{METHODS}

\section{Participants}

Cannabis users were recruited by print, radio and television advertisements. For the present research, we chose experienced cannabis smokers, aged $21-45$ years, reporting multiple years of use, who exhibited a positive urine cannabinoid immunoassay test greater than 100 $\mathrm{ng} / \mathrm{mL}$ prior to admission to the unit. Participants were excluded from the study if they displayed clinically significant medical conditions including cardiovascular, pulmonary, neurologic, endocrine, hematologic, or hepatic abnormalities. Participants provided 
voluntary written informed consent and the NIDA Institutional Review Board approved the study. Medical (physical examination, ECG, blood, and urine chemistries) and psychological evaluations including self-reported drug use history were conducted. Participants resided on the secure clinical research unit under $24 \mathrm{~h}$ medical surveillance to ensure cannabis abstinence. Access to a universal gym, exercise bike and a secure courtyard area for recreation was provided. Meals were ordered from the hospital cafeteria and no diet or liquid restrictions were imposed.

\section{Study Design}

Whole blood specimen collection-Three $\mathrm{mL}$ whole blood was collected with an indwelling venous catheter into sodium heparin BD Vacutainer® tubes at the time of admission and generally at 9 am each day thereafter for seven days. Specimens were stored at $-20^{\circ} \mathrm{C}$ until analysis.

Specimen analysis-Whole blood specimens were analyzed for cannabinoids by modification of a validated two-dimensional gas chromatography-mass spectrometry (2DGCMS) method for simultaneous THC, 11-OH-THC, and THCCOOH quantification [20]. Briefly, proteins in $1 \mathrm{~mL}$ of whole blood were precipitated with $3 \mathrm{~mL}$ cold acetonitrile while vortexing. After centrifugation, the supernatant was decanted into $5 \mathrm{~mL}$ sodium acetate buffer ( $\mathrm{pH} 4.0$ ), vortexed and applied to conditioned 200-mg ZSTHC020® solid phase extraction (SPE) columns (United Chemical Technologies, Inc.; Bristol, PA). Columns were washed with $3 \mathrm{~mL}$ deionized water, $2 \mathrm{~mL} 0.1 \mathrm{~N}$ hydrochloric acid/acetonitrile $(70: 30 \mathrm{v} / \mathrm{v})$, and dried by full vacuum for $20 \mathrm{~min}$. Analytes were eluted with $1 \times 3 \mathrm{~mL}$ and $1 \times 2 \mathrm{~mL}$ hexane:ethyl acetate $(80: 20 \mathrm{v} / \mathrm{v})$. Eluents were dried under nitrogen, reconstituted with 25

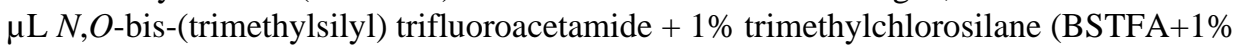
TMCS) for derivatization at $70^{\circ} \mathrm{C}$ for $30 \mathrm{~min}$.

Derivatized extracts were injected ( $3 \mu \mathrm{L}$ ) onto an Agilent 6890/5973 2D-GCMS equipped with cryofocusing and operated in electron impact/selected ion monitoring mode. 2D-GCMS provided effective separation of analyte from matrix, while cryofocusing significantly enhanced signal. Split calibration curves (low, $0.25-25$, and high, $25-100 \mathrm{ng} / \mathrm{mL}$ ) were constructed with $\mathrm{r}^{2} \geq 0.990$. Limits of quantification (LOQ) were $0.25 \mathrm{ng} / \mathrm{mL}$ for THC and $\mathrm{THCCOOH}$ and $0.50 \mathrm{ng} / \mathrm{mL}$ for 11-OH-THC. Intra-assay imprecision $(N=16$ in 4 different assays) was 1.5 to $3.7 \%$ for all analytes and inter-assay imprecision $(N=20)$ was less than $8.0 \%$

Data analysis-Statistical analyses were performed with SPSS for Windows, version 13.0 (Chicago, IL, USA) and Microsoft Excel 2002 for Windows.

Body mass index (BMI) was calculated as:

$$
\mathrm{BMI}=703 \times\left[\text { weight }(\mathrm{Ib}) / \text { height }^{2}\left(\mathrm{in}^{2}\right)\right]
$$

\section{RESULTS}

Twenty-five frequent cannabis users (12 male, 13 female; 84.0\% African American, 8.0\% Hispanic, 4.0\% Caucasian, 4.0\% American Indian; mean age, $26.2 \pm 4.5$ years; median, 25.0 years; range, 21-38 years) completed the study. Race/ethnicity was defined by the participant. Demographic and physiological characteristics of participants are reported in Table 1. Most of the participants reported daily or near daily cannabis use in the last 14 days. Mean duration of use averaged $8.8 \pm 4.4$ years with mean age of first use of $15.8 \pm 2.9$ years. Mean time since last self-reported use was $0.6 \pm 0.7$ days. Every participant reported 
drinking alcohol in the month prior to admission, and all but four (participants A, C, S and $\mathrm{X}$ ) reported smoking tobacco within two weeks of admission. No participant reported other illicit drug use during the two weeks prior to admission, with the exception of participant M, who reported using cocaine one day. [Insert Table 1 approximately here]

THC concentrations during seven days of abstinence are reported in Table 1. Nine chronic users $(36 \%)$ had no positive specimens, despite the low LOQ, throughout the seven-day abstinence period, similar to what has been documented after acute cannabis exposure. Fourteen participants were positive on admission (day 1) (Figure 1), and four (28.6\%) of these had THC concentrations above $1.0 \mathrm{ng} / \mathrm{mL}$, the cutoff frequently applied to indicate DUID in the United States. Surprisingly, on the seventh day of monitored cannabis abstinence, six full days after entering the unit, six participants' whole blood specimens contained THC $\geq 0.25 \mathrm{ng} / \mathrm{mL}$, with three $\geq 1.0 \mathrm{ng} / \mathrm{mL}$. THC concentrations always exceeded 11-OH-THC concentrations, with the exception of four participants' specimens on day 1 . A total of 20 specimens were positive for both THC and 11-OH-THC, with only one positive for 11-OH-THC without THC. All participants exhibited measurable THCCOOH concentrations throughout seven days of abstinence (Table 2). [Insert Table 2 and Figure 1 approximately here]

Five participants, all female, were THC positive throughout the seven days (Table 1). Among these five individuals, THC, 11-OH-THC, and THCCOOH concentrations ( \pm SE) on day 1 were $2.5 \pm 1.1,1.9 \pm 1.1$, and $45.2 \pm 15.0 \mathrm{ng} / \mathrm{mL}$, respectively. Day 7 cannabinoid blood concentrations were $1.5 \pm 0.5,0.3 \pm 0.2$, and $18.7 \pm 6.1 \mathrm{ng} / \mathrm{mL}$, respectively.

For the first time to our knowledge, negative whole blood specimens were found interspersed between positive samples (Table 1 and Figure 2). Of the 16 participants with positive specimens, two (12.5\%) had THC concentrations less than LOQ at admission, but at least one later positive specimen. Participants' data displayed different patterns (Figure 2). For instance, participant O's blood was THC negative at admission and on day 3, but THC was detectable on days 2, 4, 5 and 6 (Figure 2a). Participant U's THC blood concentrations decreased daily until no drug was detectable on day 7 (Figure 2b), while participant S's THC concentrations were the highest obtained on each day and exceeded $2.2 \mathrm{ng} / \mathrm{mL}$ for the entire seven days (Figure 2c). We found no significant correlation between BMI and time until the last THC-positive whole blood specimen $(\mathrm{R}=-0.2 ; p=0.445)$. [Insert Figure 2 approximately here]

\section{DISCUSSION}

We assessed whole blood THC concentrations in 25 frequent cannabis users living on a secure research unit with $24 \mathrm{~h}$ medical surveillance during seven days of cannabis abstinence. Some of these users displayed substantial whole blood THC concentrations after at least seven days of abstinence. This finding is in accordance with Johansson et al, who found measurable THC in plasma of three males up to 13 days after $60 \mathrm{mg}$ smoked THC, administered over two days. [21] There were few 11-OH-THC-positive specimens. Oral THC (Marinol) produces approximately equivalent THC and 11-OH-THC concentrations after first pass metabolism in the liver [5,22] -- but when cannabis is smoked, efficient gas exchange in the lungs distributes THC into systemic circulation yielding only about $10 \% 11$ OH-THC. In contrast, THCCOOH was detectable in this study in all participants for at least seven days. This is consistent with previous studies reporting prolonged $\mathrm{THCCOOH}$ urinary excretion in frequent cannabis users [23-26].

Whole blood THC concentrations were highly variable among participants; nine participants had no quantifiable THC at any time, whereas others displayed substantial THC 
concentrations even after seven days. Variable THC release rates from tissue stores during abstinence may account for these marked variations. It is interesting to note that of the five participants with positive THC specimens on all seven days, all were female. Although previous studies have reported no differences in THC metabolism, disposition and kinetics between sexes [5], we have recently reported that the time to last positive THCCOOH in urine was $140 \mathrm{~h}$ longer in 10 abstinent females as compared to 12 males ( $\mathrm{p}<0.02)$ [27]. In the present study, there was no significant difference in BMI between males and females; however, females generally have more adipose tissue than males and possibly, these women had a greater THC body burden. Interestingly, participant $\mathrm{S}$, who showed the highest THC concentrations, had the lowest BMI among the women in the study - suggesting that factors other than BMI, such as neuroendocrine effects, might account for differences between individuals and between the sexes. Although we did not assess body fat percentage among our subjects, this measure should be considered in future excretion studies.

Clearly, cannabis produces impairment in neurocognitive and psychomotor skills necessary for safe driving; however, defining the relationship between THC blood concentrations and performance decrements has been challenging. Numerous early studies failed to find a significant increase in accident risk when cannabinoids were present in blood or urine [2833]. In some of these, the presence of the non-psychoactive THCCOOH metabolite, rather than THC, defined recent cannabis use. Other limitations included long intervals between accident occurrence and blood collection leading to false negative cannabinoid results, and limited numbers of cases positive for cannabis only. More recently, Drummer et al. conducted a study in 3398 fatally injured drivers to determine the effect of cannabis on accident culpability [34]. Using a validated method of classifying drivers as culpable or nonculpable, the investigators found that accident risk significantly increased in drivers with measurable blood THC concentrations (no LOQ provided) when compared to drug-free drivers (odds ratio (OR) 2.7, 95\% confidence interval (CI) 1.0 - 7.0). When THC concentrations were greater than $5 \mathrm{ng} / \mathrm{mL}$, culpability increased (OR 6.6, 95\% CI 1.5 28.0). This odds ratio is comparable to that observed with a blood alcohol concentration of $0.15 \mathrm{~g} \%$.

Recent experimental laboratory research proposed impairment limits of $2-5 \mathrm{ng} / \mathrm{mL}$ serum THC (approximately $1-2.5 \mathrm{ng} / \mathrm{mL}$ whole blood) after observing behavioral impairment in a majority of participants with serum THC concentrations within the suggested limits in tasks relating to driving skills [35]. Others suggested that a serum THC between 7 and $10 \mathrm{ng} / \mathrm{mL}$ (approximately $3.5-5.0 \mathrm{ng} / \mathrm{mL}$ whole blood) was indicative of impairment, similar to a BAC of $0.05 \%$ based on a meta-analysis of multiple toxicological studies [36]. But it is difficult to apply these limits in the field, because THC concentrations decrease rapidly after cannabis smoking, even in frequent users, from high peak concentrations (100 to $400 \mathrm{ng} / \mathrm{mL}$ depending upon the individual, cannabis potency, and smoking parameters) to levels of 1 to $10 \mathrm{ng} / \mathrm{mL}$ in a few hours. The time required to obtain biological specimens after automobile or industrial accidents often exceeds $3 \mathrm{~h}$, frequently leading to negative THC tests. Drug concentrations in the majority of DUID cases are $1-2 \mathrm{ng} / \mathrm{mL}$. If a $5 \mathrm{ng} / \mathrm{mL}$ whole blood limit had been the law, $77-90 \%$ of apprehended drivers recently using cannabis in Sweden from $1995-2004$ would not have been prosecuted [37]. Conversely, as the present study shows, some individuals may display concentrations well over $1 \mathrm{ng} / \mathrm{mL}$ many days after last cannabis exposure.

One limitation of our research is reliance on self-reports of drug use; reports of the recency and quantity of cannabis smoked often did not correlate with analyte concentrations.

However, this limitation would not impact our principal finding that substantial blood THC concentrations persisted for days in many chronic cannabis users. Another possible limitation of the study is that specimens were kept in long-term frozen storage for up to five 
years prior to analysis, raising the possibility of degradation of cannabinoids in whole blood specimens. For example, analytes may have adsorbed to polypropylene storage tubes [38], precipitated with blood proteins, or degraded in vitro. Whole blood cannabinoid stability is variable [38-40]. A recent study [41] has observed cannabinoid concentration decreases of a least $20 \%$ in spiked whole blood stored at $-20^{\circ} \mathrm{C}$ for two weeks, while a separate study [39] has observed no statistically significant decreases after six months in fortified blood stored at $-10^{\circ} \mathrm{C}$. However, these factors could only have caused us to underestimate, rather than overestimate cannabinoid concentrations. Also, these stability studies were conducted in blank whole blood fortified with cannabinoids and not in authentic specimens that were collected and analyzed in the current study.

In summary, we found highly variable, but often substantial whole blood THC concentrations in chronic cannabis users for many days after last drug exposure. These findings may be relevant for legislation employing THC concentrations to define intoxication and accident culpability. The findings also raise the intriguing possibility that cannabis-associated cognitive and motor impairment, demonstrated in some individuals for many days after last cannabis exposure [16,17,42-44], may be related to the persistence of THC in the blood and by implication, in the brain [45]. If so, our findings suggest that residual neurocognitive impairment after days of abstinence might be quite variable among individuals, depending on the persistence and magnitude of THC in an individual's brain. These data suggest a potential mechanism for cognitive impairment after chronic cannabis use and provide data for evidence-based policy decisions on DUID. In subsequent studies, it will be invaluable to assess the association between neuropsychological performance and simultaneous blood THC concentrations. If neurocognitive impairment is documented after at least seven days of abstinence, the implementation of per se impairment limits may be valid.

\section{Acknowledgments}

The authors would like to thank Allan J. Barnes for data analysis support and Kathleen Demuth, Janeen Nichels and John Etter for clinical research assistance. This research was supported by the Intramural Research Program of the National Institute on Drug Abuse, National Institutes of Health.

\section{REFERENCES}

1. Huestis MA, Gorelick DA, Heishman SJ, Preston KL, Nelson RA, Moolchan ET, et al. Blockade of effects of smoked marijuana by the CB1-selective cannabinoid receptor antagonist SR141716. Arch Gen Psychiatry. 2001; 58:322-330. [PubMed: 11296091]

2. Perez-Reyes M, Timmons MC, Lipton MA, Davis KH, Wall ME. Intravenous injection in man of delta-9-tetrahydrocannabinol and 11-OH-delta-9-tetrahydrocannabinol. Science. 1972; 177:633635. [PubMed: 4558903]

3. Bland TM, Haining RL, Tracy TS, Callery PS. CYP2C-catalyzed delta9-tetrahydrocannabinol metabolism: kinetics, pharmacogenetics and interaction with phenytoin. Biochem Pharmacol. 2005; 70:1096-1103. [PubMed: 16112652]

4. Watanabe K, Yamaori S, Funahashi T, Kimura T, Yamamoto I. Cytochrome P450 enzymes involved in the metabolism of tetrahydrocannabinols and cannabinol by human hepatic microsomes. Life Sci. 2007; 80:1415-1419. [PubMed: 17303175]

5. Wall ME, Sadler BM, Brine D, Taylor H, Perez-Reyes M. Metabolism, disposition, and kinetics of delta-9-tetrahydrocannabinol in men and women. Clin Pharmacol Ther. 1983; 34:352-363. [PubMed: 6309462]

6. Huestis MA, Henningfield JE, Cone EJ. Blood cannabinoids. I. Absorption of THC and formation of 11-OH-THC and THCCOOH during and after smoking marijuana. J Anal Toxicol. 1992; 16:276-282. [PubMed: 1338215] 
7. Huestis MA, Henningfield JE, Cone EJ. Blood cannabinoids. II. Models for the prediction of time of marijuana exposure from plasma concentrations of delta-9-tetrahydrocannabinol (THC) and 11nor-9-carboxy-delta-9-tetrahydrocannabinol (THCCOOH). J Anal Toxicol. 1992; 16:283-290. [PubMed: 1338216]

8. Huestis MA, Elsohly M, Nebro W, Barnes A, Gustafson RA, Smith ML. Estimating time of last oral ingestion of cannabis from plasma THC and THCCOOH concentrations. Ther Drug Monit. 2006; 28:540-544. [PubMed: 16885722]

9. Huestis MA, Barnes A, Smith ML. Estimating the time of last cannabis use from plasma delta9tetrahydrocannabinol and 11-nor-9-carboxy-delta9-tetrahydrocannabinol concentrations. Clin Chem. 2005; 51:2289-2295. [PubMed: 16223887]

10. Ramaekers JG, Berghaus G, Van Laar M, Drummer OH. Dose related risk of motor vehicle crashes after cannabis use. Drug Alcohol Depend. 2004; 73:109-119. [PubMed: 14725950]

11. Block RI, Farinpour R, Braverman K. Acute effects of marijuana on cognition: relationships to chronic effects and smoking techniques. Pharmacology Biochemistry \& Behavior. 1992; 43:907917.

12. Chait LD, Perry JL. Acute and residual effects of alcohol and marijuana, alone and in combination, on mood and performance. Psychopharmacology (Berl). 1994; 115:340-349. [PubMed: 7871074]

13. Riedel, G.; Davies, SN. Cannabinoid function in learning, memory and plasticity. In: Pertwee, RG., editor. Handbook of Experimental Pharmacology. New York: Springer; 2005. p. 446-470.

14. Hall W, Solowij N. Adverse effects of cannabis. The Lancet. 1998; 352:1611-1616.

15. Hampson RE, Deadwyler SA. Cannabinoids, hippocampal function and memory. Life Sci. 1999; 65:715-723. [PubMed: 10462072]

16. Pope HG, Gruber AJ, Hudson JI, Huestis MA, Yurgelun-Todd D. Cognitive measures in long-term cannabis users. J Clin Pharmacol. 2002; 42:41S-47S. [PubMed: 12412835]

17. Pope H, Gruber A, Hudson J, Huestis M, Yurgelun-Todd D. Neuropsychological performance in long-term cannabis users. Arch Gen Psychiatry. 2001; 58:909-915. [PubMed: 11576028]

18. Peat, MA. Distribution of delta-9-tetrahydrocannabinol and its metabolites. In: Baselt, RC., editor. Advances in Analytical Toxicology II. Chicago: Year Book Medical Publishers; 1989. p. 186-217.

19. Skopp G, Potsch L. Cannabinoid concentrations in spot serum samples 24-48 hours after discontinuation of cannabis smoking. J Anal Toxicol. 2008; 32:160-164. [PubMed: 18334100]

20. Lowe RH, Karschner EL, Schwilke EW, Barnes AJ, Huestis MA. Simultaneous quantification of delta-9-tetrahydrocannabinol (THC), 11-hydroxy-delta-9-tetrahydrocannabinol (11-OH-THC), and 11-nor-delta-9-tetrahydrocannabinol-9-carboxylic acid (THCCOOH) in human plasma using twodimensional gas chromatography, cryofocusing, and electron impact-mass spectrometry. J Chromatogr A. 2007; 1163:318-327. [PubMed: 17640656]

21. Johansson E, Agurell S, Hollister LE, Halldin MM. Prolonged apparent half-life of delta-1tetrahydrocannabinol in plasma of chronic marijuana users. J Pharm Pharmacol. 1988; 40:374375. [PubMed: 2899638]

22. Frytak S, Moertel CG, Rubin J. Metabolic studies of delta-9-tetrahydrocannabinol in cancer patients. Cancer Treat Rep. 1984; 68:1427-1431. [PubMed: 6095996]

23. Ellis GM, Mann MA, Judson BA, Schramm NT, Tashchian A. Excretion patterns of cannabinoid metabolites after last use in a group of chronic users. Clin Pharmacol Ther. 1985; 38:572-578. [PubMed: 3902318]

24. Dackis CA, Pottash AIC, Annitto W, Gold MS. Persistence of urinary marijuana levels after supervised abstinence. Am J Psychiatry. 1982; 139:1196-1198. [PubMed: 6287871]

25. Cridland JS, Rottanburg D, Robins AH. Apparent half-life of excretion of cannabinoids in man. Hum Toxicol. 1983; 2:641-644. [PubMed: 6642522]

26. Goodwin RS, Darwin WD, Chiang CN, Shih M, Li S-H, Huestis MA. Urinary Elimination of 11Nor-9-Carboxy- $\Delta$ 9-tetrahydrocannabinol in Cannabis Users During Continuously Monitored Abstinence. J Anal Toxicol. 2008; 32:562-566. [PubMed: 19007504]

27. Darwin, WD.; Herning, RI.; Bolla, K.; Cadet, JL.; Huestis, MA. A Comparison by Gender of Urinary Elimination of 11-nor-9-carboxy- $\Delta$ 9-tetrahydrocannnabinol (THCCOOH) in Cannabis Users. Paper presented at the Society of Forensic Toxicologists Annual Meeting - 2007; October 15-19, 2007; Durham, NC. 2007. 
28. Terhune KW, Fell JC. The role of alcohol, marijuana, and other drugs in the accidents of injured drivers. US Department of Transportation. 1982

29. Terhune KW, Ippolito DL, Hendricks DL, Michalovic JG, Bogema SC, Santinga P, et al. The incidence and role of drugs in fatally injured drivers. US Department of Transportation/National Highway Traffic Safety Administration. 1992 October. 1-K1.

30. Williams AF, Peat MA, Crouch DJ, Wells JK, Finkle BS. Drugs in fatally injured young male drivers. Public Health Rep. 1985; 100:19-25. [PubMed: 3918318]

31. Drummer OH. Drugs in drivers killed in Australian road traffic accidents. Victorian Institute of Forensic Medicine. 1994

32. Hunter CE, Loken RJ, Longo MC. The prevalence and role of alcohol, cannabinoids, benzodiazepines and stimulants in non-fatal crashes. South Austrialian Forensic Science. 1998

33. Lowenstein SR, Koziol-Mclain J. Drugs and traffic crash responsibility: a study of injured motorists in Colorado. The Journal of Trauma Injury, Infection, and Critical Care. 2001; 50:313320.

34. Drummer OH, Gerostamoulos J, Batziris H, Chu M, Caplehorn J, Robertson MD, et al. The involvement of drugs in drivers of motor vehicles killed in Australian road traffic crashes. Accid Anal Prev. 2004; 36:239-248. [PubMed: 14642878]

35. Ramaekers JG, Moeller MR, Van Ruitenbeek P, Theunissen EL, Schneider E, Kauert G. Cognition and motor control as a function of Delta9-THC concentration in serum and oral fluid: limits of impairment. Drug Alcohol Depend. 2006; 85:114-122. [PubMed: 16723194]

36. Grotenhermen F, Leson G, Berghaus G, Drummer OH, Kruger HP, Longo M, et al. Developing limits for driving under cannabis. Addiction. 2007; 102:1910-1917. [PubMed: 17916224]

37. Jones AW, Holmgren A, Kugelberg FC. Driving under the influence of cannabis: a 10-year study of age and gender differences in the concentrations of tetrahydrocannabinol in blood. Addiction. 2008; 103:452-461. [PubMed: 18190663]

38. Christophersen AS. Tetrahydrocannabinol stability in whole blood: plastic versus glass containers. J Anal Toxicol. 1986; 10:129-131. [PubMed: 3018361]

39. Johnson JR, Jennison TA, Peat MA, Foltz RL. Stability of delta-9-tetrahydrocannabinol (THC), 11-hydroxy-THC, and 11-nor-9-carboxy-THC in blood and plasma. J Anal Toxicol. 1984; 8:202204. [PubMed: 6094914]

40. Wong, AS.; Orbanosky, MW.; Reeve, VC.; Beede, JD. Analysis of cannabinoids Research Monograph. Rockville: National Institute on Drug Abuse; 1982. Stability of delta-9tetrahydrocannabinol in stored blood and serum; p. 119-124.

41. Schwilke EW, Karschner EL, Lowe RH, Gordon AM, Cadet JL, Herning R, et al. Intra- and Intersubject Whole Blood/Plasma Cannabinoid Ratios Determined by 2-Dimensional, Electron ImpactGas Chromatography, Mass Spectrometry with Cryofocusing. Clin Chem. 2008 in Press.

42. Pope HG, Yurgelun-Todd D. The residual cognitive effects of heavy marijuana use in college students. JAMA. 1996; 275:521-527. [PubMed: 8606472]

43. Bolla KI, Brown K, Eldreth D, Tate K, Cadet JL. Dose-related neurocognitive effects of marijuana use. Neurology. 2002; 59:1337-1343. [PubMed: 12427880]

44. Solowij N, Stephens RS, Roffman RA, Babor T, Kadden R, Miller M, et al. Cognitive functioning of long-term heavy cannabis users seeking treatment. JAMA. 2002; 287:1123-1131. [PubMed: 11879109]

45. Mura P, Kintz P, Dumestre V, Raul S, Hauet T. THC can be detected in brain while absent in blood. J Anal Toxicol. 2005; 29:842-843. [PubMed: 16356342] 


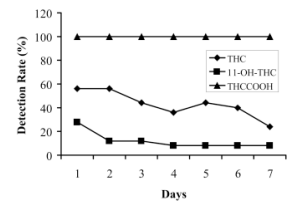

Figure 1.

Detection rate percentages of $\Delta 9$-tetrahydrocannabinol (THC), 11-hydroxy-9-THC (11-OHTHC) and 11-nor-9-carboxy-THC (THCCOOH) in whole blood of participants $(N=25)$ over 7 days of continuously monitored cannabis abstinence. LOQ for THC and THCCOOH $0.25 \mathrm{ng} / \mathrm{mL}$ and $11-\mathrm{OH}-\mathrm{THC} 0.50 \mathrm{ng} / \mathrm{mL}$. 


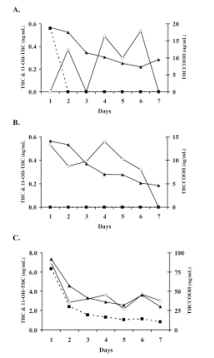

Figure 2.

Representative patterns of $\Delta$ 9-tetrahydrocannabinol (THC) ( $)$, 11-hydroxy-9-THC (11-OHTHC) (घ) and 11-nor-9-carboxy-THC (THCCOOH) ( $\boldsymbol{\Delta}$ ) excretion. Participant O (panel A), $\mathrm{U}$ (panel B) and S (panel C) whole blood cannabinoid concentrations during 7 days of continuously monitored cannabis abstinence. 


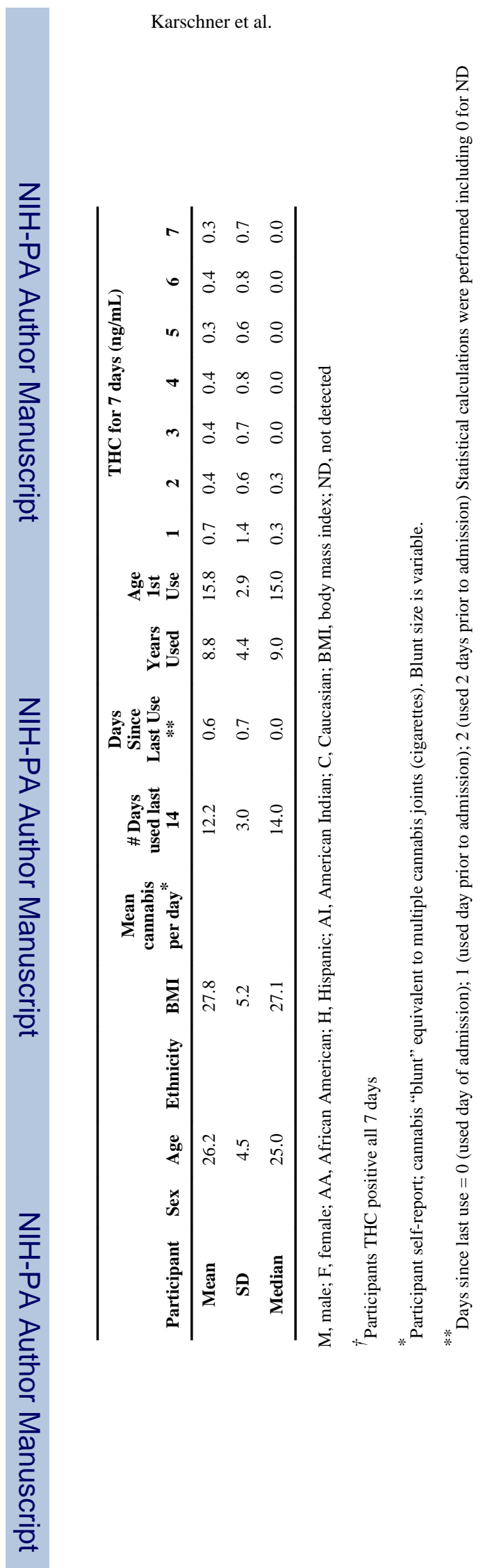

Addiction. Author manuscript; available in PMC 2010 December 1. 


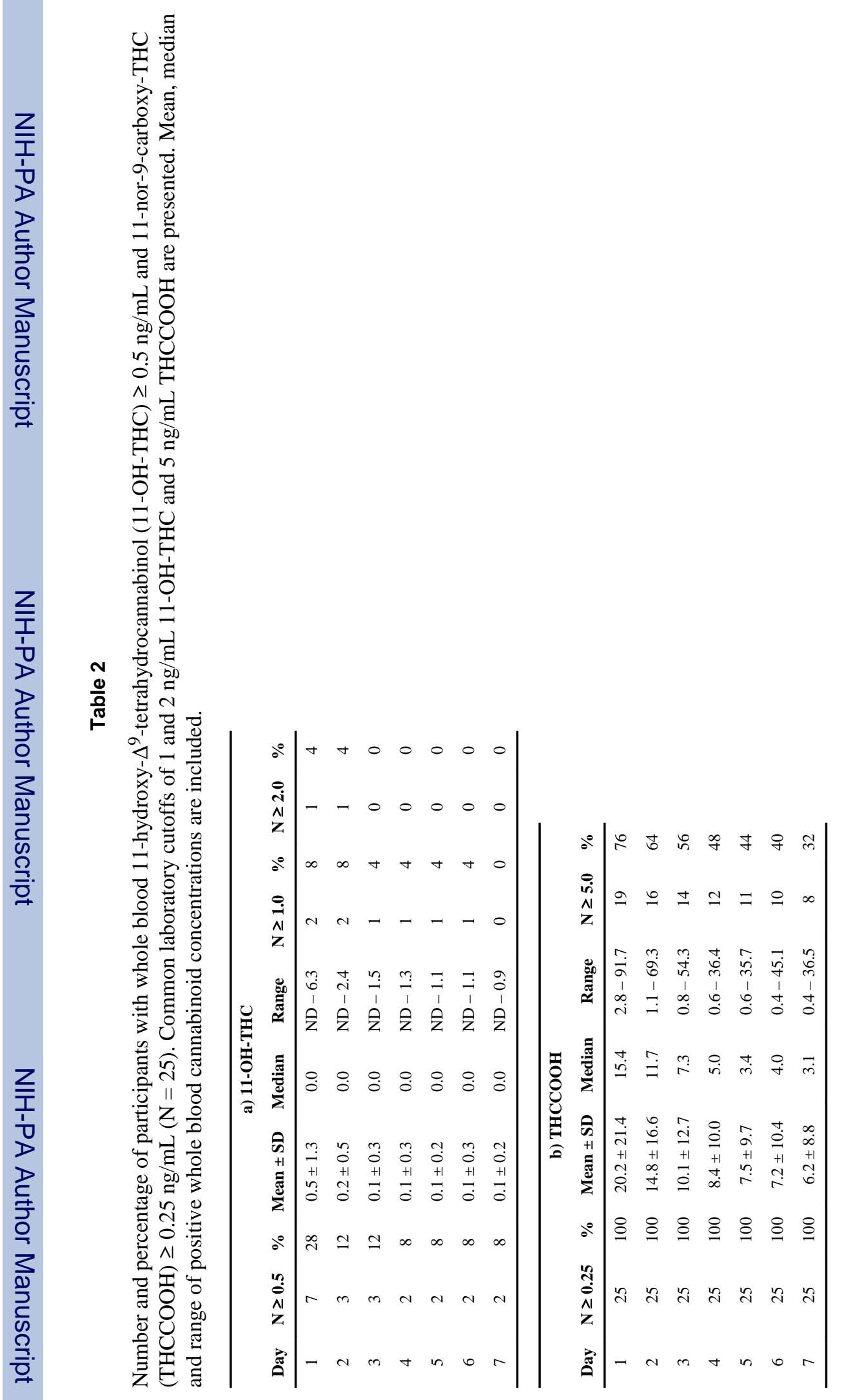

